\title{
Using the Hitachi TM 3000 in a middle school classroom
}

\section{Mary Ellen Wolfinger}

Mary Ellen Wolfinger, "Using the Hitachi TM 3000 in a middle school classroom," Proc. SPIE 8729, Scanning Microscopies 2013: Advanced Microscopy Technologies for Defense, Homeland Security, Forensic, Life, Environmental, and Industrial Sciences, 87290D (29 May 2013); doi: $10.1117 / 12.2016185$

Event: SPIE Defense, Security, and Sensing, 2013, Baltimore, Maryland, United States 


\title{
Using the Hitachi TM 3000 in a Middle School Classroom
}

\author{
Mary Ellen Wolfinger \\ Takoma Park Middle School, Silver Spring, MD
}

\begin{abstract}
In this presentation, Mary Ellen Wolfinger explains how the Hitachi TM 3000 scanning electron microscope was used in her sixth grade science classroom to incorporate science, technology, engineering and mathematics (STEM) education .
\end{abstract}

\subsection{Introduction}

In fall 2011, middle school teachers participated in a Science Afternoon at the National Institute of Standards and Technology (NIST) with Mary Satterfield (NIST) and Robert Gorman (Hitachi). Teachers used the Hitachi TM 3000 as well as scanning electron microscopes used by NIST scientists.

Teachers brought objects to view with the Hitachi TM 3000 and were taught how to run the controls in order to see a focused image of their object on the attached computer. The afternoon also included a tour of some of NIST's SEM labs where teachers met scientists, learned about the powerful SEMs and how the microscopes are being used in research such as studying metals. Teachers got hands-on experience and learned how to use the SEM to look closely at a cricket by adjusting the magnification and focus.

After the science afternoon at NIST, some teachers arranged to have the Hitachi TM 3000 in their classroom for student use.

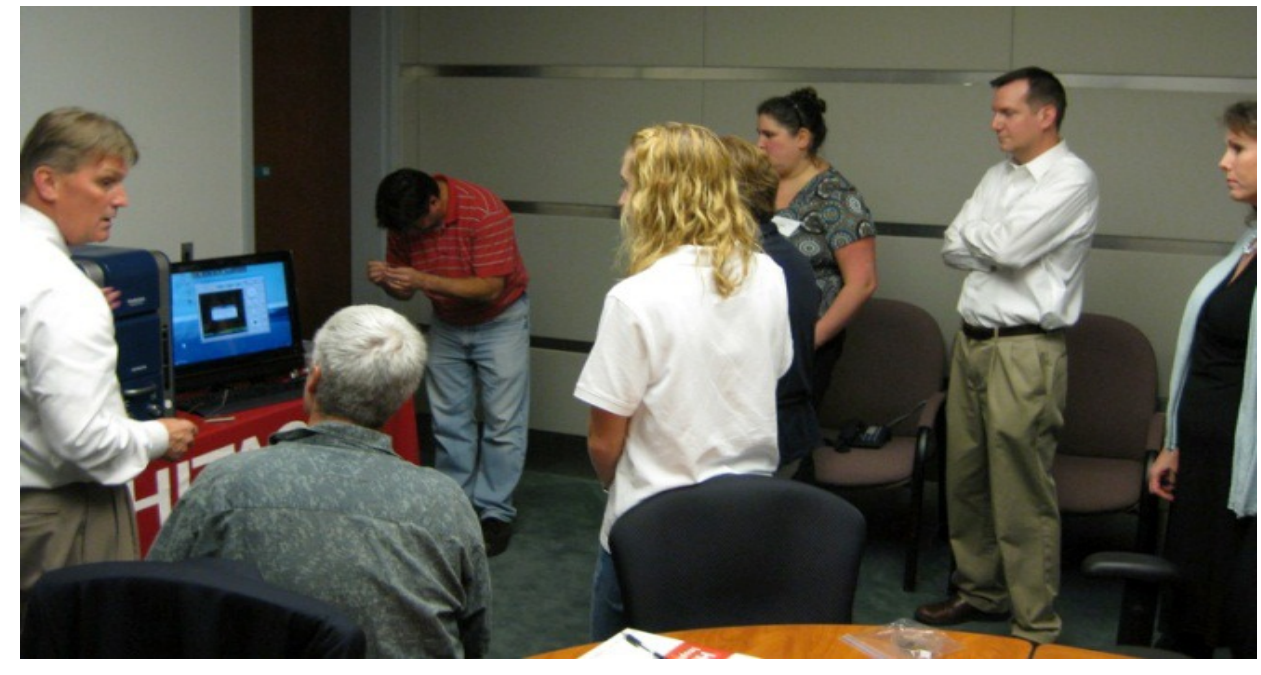

Figure 1. Teachers learning to use the Hitachi TM 3000 at Science Afternoon at NIST. (photo by Mary Satterfield) 


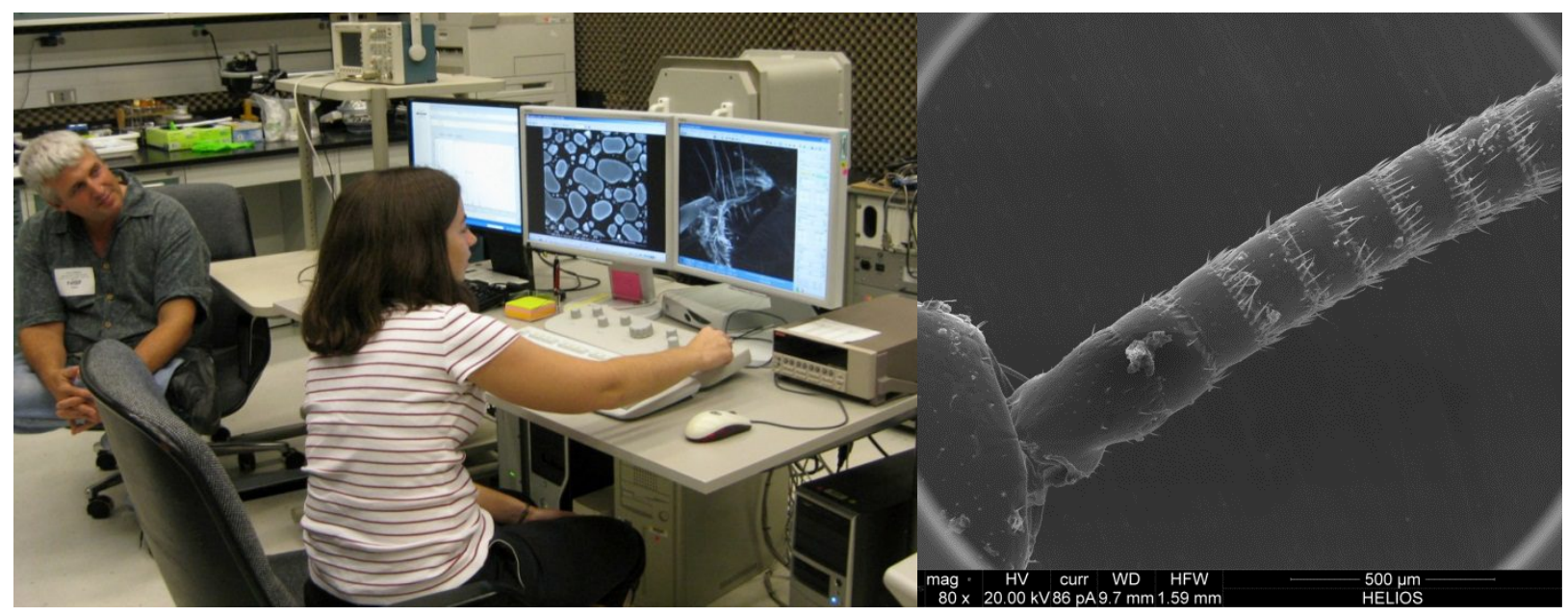

Figure 2. Teachers use the FEI-Helios Dual Beam Focused Ion Beam SEM at NIST. (photo by Mary Satterfield) Image of a cricket antenna, using the FIB.

\subsection{Takoma Park Middle School}

Takoma Park Middle School is a public middle school in Montgomery County Maryland. Takoma Park Middle School houses the Math, Science and Computer Science Magnet Program for half of Montgomery County. About half of the school population is comprised of students who apply to the magnet program, many from outside of the Takoma Park school boundaries. Only students with the strongest math and science scores and teacher recommendations are accepted to the program. The remaining members of the student body are students from the local community. Mary Ellen Wolfinger teaches sixth grade science to the students in the comprehensive (local) program. Because of the two very different science curriculums, it is even more important for students in the comprehensive program to have access to quality STEM instruction.
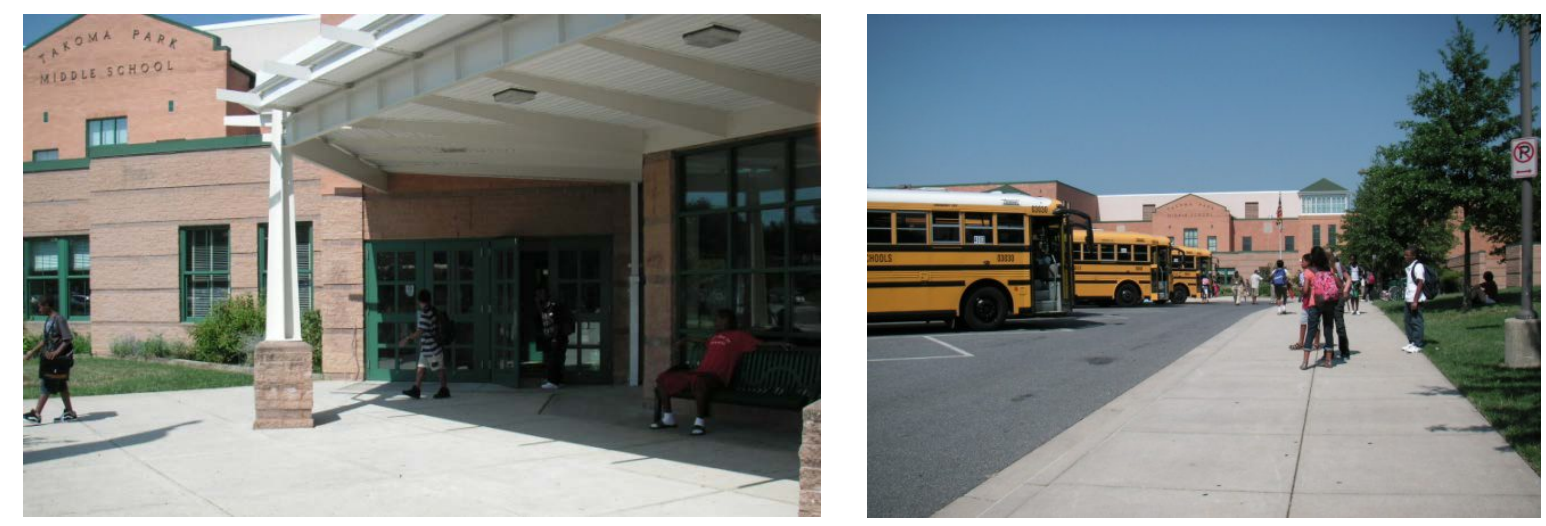

Figure 3. Takoma Park Middle School is located in Silver Spring, MD. 


\subsection{Hitachi TM 3000 in the Classroom}

Mary Ellen Wolfinger arranged to have the Hitachi TM 3000 in her sixth grade science classroom in May of 2012. For one week, students used the table top microscope in conjunction with other activities about nanotechnology. Each class participated in a lesson about the basic operation of an electron microscope and nanotechnology vocabulary.

In addition to working the Hitachi TM 3000 to look at selected objects, students read Science is Fun: All About Electron Microscopes, a booklet by Hitachi and Nanooze, a magazine by the Cornell NanoScale Science and Technology Facility. A nanotech puzzle matching equivalent measurements and an activity to find the nanotechnology measurements of common objects.

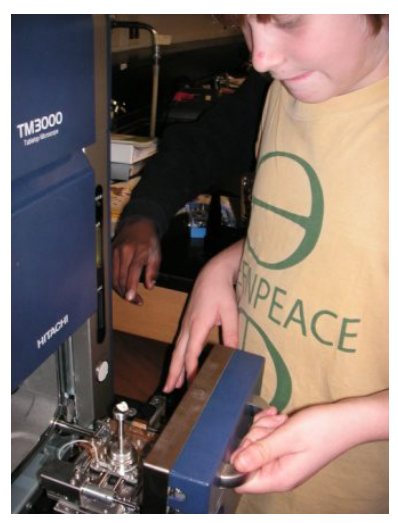

Figure 4. A student places a sample in the Hitachi TM 3000.

\subsection{Hitachi TM 3000 at STEM Night}

STEM night is held annually at Takoma Park Middle School. STEM night is an evening community event featuring student science projects, guest scientists, high school robotics team and health careers students and science trivia challenges. The timing of the Hitachi TM 3000 in the classroom was scheduled to coincide with STEM Night 2012.

Mary Ellen Wolfinger opened her classroom as one of the interactive opportunities at STEM night. Students, parents, siblings and community members took advantage of running the SEM to take a closer look at available specimens or tissue, hair, insects, flowers and other objects. The parents with background knowledge or professional use of electron microscopes were excited to interact with the Hitachi TM 3000 with their children and talk with other parents about how the SEM worked. Literature from Hitachi about the TM 3000 was available and read by many interested visitors. Many of the parents expressed how impressed they were that such an advanced instrument was used in a middle school classroom, a reality that was underappreciated by many of the students.

As children used the Hitachi TM 3000, the difference between optical light microscopes and electron microscopes was highlighted. Many of the school aged children had used optical microscopes in school or at home and seemed to understand that we can see smaller things with the electron microscope, because electrons are smaller than light. 


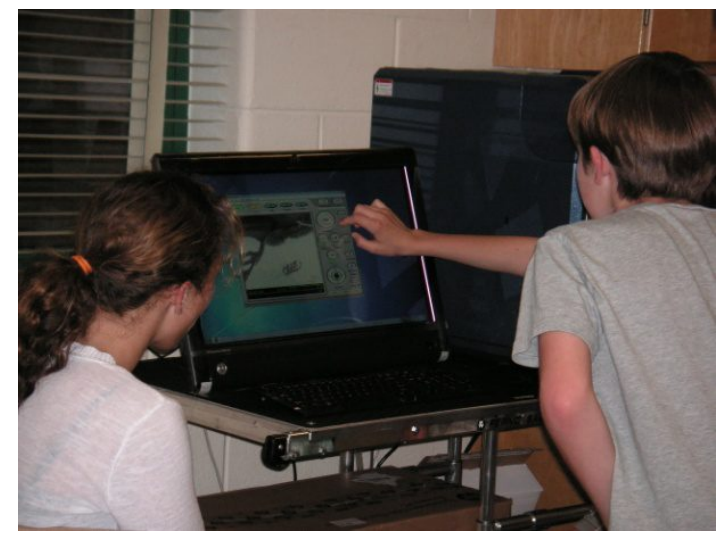

Figure 5. Students at STEM night use the Hitachi TM 3000 to magnify an insect they brought to look at using the SEM.

\subsection{Conclusion}

Having the Hitachi TM 3000 in the middle school classroom was a successful way for students to interact with advanced technology and introduce nontechnology. Students learned new measurement vocabulary, more about how microscopes work, looked at and measured specimens of their choice and shared their experience with their families. Using the Hitachi TM 3000 was memorable because many students asked about having the SEM again a year later. The Hitachi TM 3000 could be used by math students learning decimals, measurement or dimensional analysis or science students to measure small difference in the items of their choice. Now that the middle school students have learned how to use the Hitachi TM 3000, they should design their own experiment utilizing the SEM as a measurement tool. The Hitachi TM 3000 is a great way to incorporate STEM into the classroom because it makes advanced science and technology accessible to all students and provides opportunities for students to explore and observe the objects of their choice making math and science relevant to students of diverse interests.
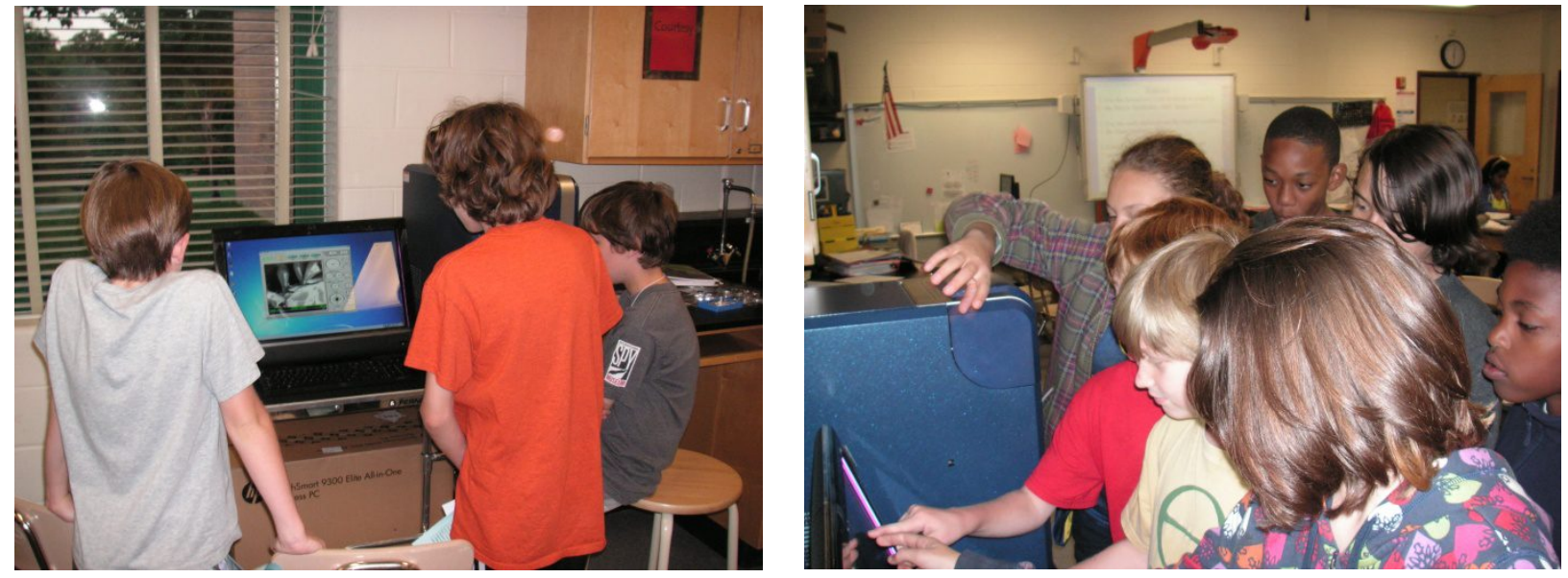

Figure 6. Students at STEM night using the Hitachi TM 3000. Students using the SEM in science class. 